\title{
PENINGKATAN EMPATI PESERTA DIDIK KELAS VII B SMP STELLA MATUTINA SALATIGA MELALUI BIMBINGAN KELOMPOK TAHUN 2018/2019
}

\author{
Fita Rahmawati ${ }^{1}$, Seytorini ${ }^{2}$, Sapto Irawan $^{3}$ \\ ${ }^{1}$ Program Studi Bimbingan dan Konseling Universitas Kristen Satya Wacana Salatiga \\ Email: 132015603@student.uksw.edu \\ ${ }^{2}$ Program Studi Bimbingan dan Konseling Universitas Kristen Satya Wacana Salatiga \\ ${ }^{3}$ Program Studi Bimbingan dan Konseling Universitas Kristen Satya Wacana Salatiga
}

\begin{abstract}
Abstrak: Penelitian bertujuan untuk mengetahui signifikansi peningkatan empati peserta didik kelas VII B di SMP Stella Matutina Salatiga melalui bimbingan kelompok. Metode penelitian ini menggunakan eksperimen dengan desain eksperimen Pretest-posttest Control Group Desain. Subjek penelitian dalam penelitian ini adalah 12 peserta didik kelas VII B di SMP Stella Matutina Salatiga yang memiliki empati yang sedang dan rendah. Kemudian jumlah peserta didik yang memiliki empati sedang dan rendah dibagi menjadi dua kelompok yaitu kelompok kontrol 6 peserta didik dan kelompok eksperimen 6 peserta didik. Pelaksanaan bimbingan kelompok dimulai pada tanggal 8 februari 2019 dan diakhiri tanggal 8 maret 2019. Bimbingan kelompok dilaksanakan 35 menit setiap pertemuan sebanyak 8 kali pertemuan. Sebelum diberikan treatment mean pada kelompok eksperimen sebesar 6,33 dan mean pada kelompok kontrol 6,67. Berdasarkan hasil uji Mann Whitney U diperoleh score Z $=-2,402, \quad \mathrm{P}=0,016 \quad(\mathrm{P} \leq 0,05)$, maka terdapat perbedaan yang signifikan antara kelompok eksperimen dan kelompok kontrol. Setelah diberikan treatment terdapat peningkatan mean rank sebesar 5,00, dari pre test 4.00 dan post test sebesar 9,00. Peningkatan empati terjadi karena adanya treatment berupa bimbingan kelompok yang dilakukan oleh kelompok eksperimen. Hal ini menunjukkan bahwa bimbingan kelompok dapat meningkatkan empati peserta didik SMP Stella Matutina Salatiga.
\end{abstract}

Kata kunci: Empati, Bimbingan kelompok, Role Play

\begin{abstract}
The study aims to determine the significance of the increase in empathy of students of class VII B at Stella Matutina Middle School in Salatiga through group guidance. This research method uses experiments with experimental designs of the Group Design Control Pretest-posttest. The research subjects in this study were 12 students of class VII B at Stella Matutina Middle School Salatiga who had moderate and low empathy. Then the number of students who have moderate and low empathy is divided into two groups, namely the control group 6 students and the experimental group 6 students. The group guidance program starts on February 8, 2019 and ends on March 8, 2019. Group guidance is carried out 35 minutes each meeting in 8 meetings. Before being given treatment the mean in the experimental group was 6.33 and the mean in the control group was 6.67. Based on the results of the Mann Whitney $U$ test obtained a $\mathrm{Z}$ score $=-2.402, \mathrm{P}=0.016(\mathrm{P} \leq 0.05)$, then there were significant differences between the experimental group and the control group. After being given treatment there is a mean rank increase of 5.00, from pre test 4.00 and post test at 9.00. Increased empathy occurs because there is a treatment in the form of group guidance carried out by the experimental group. This shows that group guidance can increase the empathy of students in Salatiga's Stella Matutina Middle School.
\end{abstract}

Keywords: Empathy, Group Guidance, Role Play 


\section{PENDAHULUAN}

Masa remaja adalah masa yang harus dilalui setiap individu untuk akhirnya mencapai kedewasaan. Menurut Havighurst (Hurlock, 1980) tugas perkembangan pada masa remaja yang berhubungan dengan kehidupan sosial adalah mencapai hubungan yang lebih matang dengan teman sebaya baik wanita maupun pria. Dalam menyelesaikan tugas perkembangannya tersebut remaja harus melakukan interaksi sosial. Tentu dalam interaksi sosial tersebut dibutuhkan empati.

Setiap individu diharapkan untuk mampu memahami perasaan orang lain dengan baik. Dalam hidup bermasyarakat empati sangat berperan penting karena dengan empati individu dapat menyesuaikan diri, mudah menjalin hubungan dengan orang lain, meningkatkan solidaritas, dan meningkatkan keharmonisan dalam menjalin hubungan sesama makhluk hidup. Menurut Davis (dalam Howe 2015) menyatakan empati adalah mengetahui apa yang dirasakan orang lain dan merasakan apa yang dirasakan orang lain, selain itu juga dapat mengkomunikasikan dengan cara dan sikap yang baik, pengetahuan dan pemahaman kita tentang pengalaman emosional orang lain tersebut. Terdapat aspek empati yang dibuat oleh Davis (Effendy, 2018) secara global ada dua komponen dalam empati yaitu: Komponen Kognitif dan komponen Afektif yang masing-masing mempunyai dua Aspek yaitu: Komponen Kognitif terdiri dari Pengambilan Perspektif/Perspektive Taking (PT) dan Fantasi/Fantacy (FS, Sedangkan komponen afektif meliputi Perhatian/Empathic Concern (EC) dan Distress Pribadi/Personal Distress (PD). Menurut Siwi dalam Taufik (2000), beberapa faktor yang mempengaruhi empati yaitu pola asuh, kepribadian, usia, derajat kematangan, sosialisasi dan jenis kelamin. Empati sangatlah penting dalam menjalin hubungan dengan orang lain ataupun pergaulan, kemampuan ini bertujuan untuk memahami perasaan orang lain, menerima sudut pandang orang lain, menghargai perbedaan perasaan orang terhadap berbagai macam hal, menjadi pendengar dan penanya yang baik (Budiningsih, 2004). Seseorang dikatakan mempunyai empati yang baik jika individu tersebut mempunyai motivasi menolong yang tinggi Maxwell (Taufik, 2012). Selain itu, Enjang (Taufik, 2012) mengungkapkan bahwa identifikasi kepada seseorang muncul sampai batas-batas tertentu dalam setiap percakapan, bahkan empati merupakan proses mendasar dalam cinta. Sikap empati sangat dibutuhkan bagi seseorang, termasuk dalam upaya menumbuhkembangkan rasa kepedulian yang mendalam kepada sesama manusia. Menurut Eisenberg (2002) sikap empati dapat ditingkatkan melalui berbagai upaya yaitu menjadi pendengar yang baik, memberi kesempatan orang lain untuk bercerita, melihat film pendek di televisi dan mencoba memikirkan pokok persoalan yang dibicarakan, bermain peran adalah teknik yang efektif dan akan membantu seseorang membentuk pemahaman yang lebih dalam, menganalisis perbedaan pendapat dengan orang lain, mencari sebab-sebab dalam diri sendiri ketika tidak menyukai seseorang.

Berdasarkan hasil observasi pada saat magang di SMP Stella Matutina Salatiga terdapat beberapa peserta didik yang menunjukkan sikap kurang empati. Hasil temuan dilapangan tersebut diantaranya sebagai berikut, terdapat diskriminasi sosial yang dilakukan peserta didik kelas VII B. Hal ini terjadi ketika peserta didik mendapatkan tugas untuk dibagi menjadi beberapa kelompok, namun hanya ada satu peserta didik laki-laki yang tidak mendapat bagian dari kelompok yang ada, bahkan hal tersebut terjadi tidak hanya sekali. Kasus lain yang terjadi di dalam kelas tersebut para peserta didik akan cenderung menertawakan terhadap teman yang kuramg dapat mengerjakan tugas di papan tulis yang diberikan guru. Masalah yang lain, tidak adanya rasa saling menghormati dan menghargai terhadap teman yang sedang presentasi di depan kelas, kebanyakan peserta didik cenderung berbicara sendiri dan kurang memperhatikan.Selain itu, ada peserta didik perempuan yang menangis sampai tersedu-sedu karena diejek temannya tetapi tidak ada satupun teman satu kelasnya yang mencoba menenangkan hal itu menandakan bahwa kepekaan atau rasa empati peserta didik dikelas itu rendah.

Berdasarkan informasi yang penulis dapatkan dari salah satu guru BK menyatakan bahwa, pada awal semester terdapat kasus diskriminasi sosial terjadi pada salah satu peserta didiknya. Kasus tersebut berawal dari seorang peserta didik laki-laki yang merasa 
bahwa tidak nyaman berada dalam kelas tersebut. Alasannya setiap kali peserta didik mendapatkan tugas untuk dibagi menjadi beberapa kelompok pasti peserta didik tersebut yang tidak mendapatkan bagian dari kelompokkelompok tersebut semakin merasa tidak nyaman karena dikucilkan oleh teman sekelasnya. Hal itu terjadi karena peserta didik tersebut mempunyai kekurangan fisik, yaitu pendengarannya kurang berfungsi dengan baik.

Dari berbagai peristiwa yang ada dapat dikatakan bahwa empati yang dimiliki beberapa peserta didik tergolong rendah, sehingga apabila perilaku tersebut dibiarkan maka akan menghambat perkembangan peserta didik selanjutnya. Salah satu solusi untuk meningkatkan empati peserta didik yang rendah tersebut adalah melalui bimbingan kelompok. Menurut Tohirin (2013) menyebutkan bahwa definisi bimbingan kelompok adalah suatu cara memberikan bantuan kepada individu melalui kegiatan kelompok. Bimbingan kelompok ditujukan untuk mencagah timbulnya masalah pada peserta didik dan mengembangkan potensi peserta didik (Romlah, 2002). Menurut Prayitno (dalam Dian, 2015) menjelaskan tujuan bimbingan kelompok terbagi menjadi 2 yaitu tujuan umum dan khusus. Tujuan umum kegiatan bimbingan kelompok adalah berkembangnya kemampuan sosialisasi siswa, khususnya kemampuan komunikasi peserta layanan sedangkan tujuan khusus bimbingan kelompok bertujuan untuk membahas topiktopik tertentu yang mengandung permasalahan actual (hangat) dan menjadi perhatian peserta. Supaya bimbingan kelompok dapat tercapai dengan baik dan sesuai harapan, maka diperlukan metode bimbingan kelompok agar dapat mudah diterima oleh siswa, salah satunya yaitu dengan metode role play. Menurut Ramayulis (dalam Istrani 2011) role play adalah penyajian bahan dengan cara memperlihatkan peragaan, baik dalam bentuk uraian maupun kenyataan. Semuanya berbentuk tingkah laku dalam hubungan sosial yang kemudian diminta beberapa peserta didik untuk memerankannya. Melalui bermain peran diharapkan siswa mengalami proses pembelajaran yang terbaik bagi dirinya, karena dapat langsung praktek untuk bersikap empati terhadap orang lain yang ada di sekitarnya.
Penelitian yang dilakukan oleh Yesi Marselina (2015), dengan judul "Layanan Bimbingan Kelompok Dengan Teknik Role Playing Untuk Meningkatkan Empati Pada Siswa Kelas VII MTs Mathla'ul Anwar Bandar Lampung Tahun Ajaran 2017/2018” mengungkapkan bahwa empati peserta didik meningkat dilihat dari mean sebelum diberikan treatment 39 dan sesudah diberikan treatment 74 sehingga terjadi peningkatan 35, dengan demikian penelitian tersebut dapat dikatakan berhasil. Selain itu, penelitian yang dilakukan oleh Siti Hasinah dengan judul “ Penerapan Bimbingan Kelompok di Sekolah Untuk Meningkatkan Empati Siswa di MAN 3 Medan 2018” mencapai keberhasilan karena pada sebelum diberikan treatment 40 dan sesudah diberikan treatment 90 sehingga terjadi peningkatan 50 .

\section{METODE}

Metode yang ditempuh dalam penelitian ini adalah eksperimen dengan desain eksperimen Pretest-posttest Control Group Desain. Subjek penelitian dalam penelitian ini adalah 12 peserta didik kelas VII B di SMP Stella Matutina Salatiga yang memiliki empati yang sedang dan rendah. Kemudian jumlah peserta didik yang memiliki empati sedang dan rendah dibagi menjadi dua kelompok yaitu kelompok kontrol 6 peserta didik dan kelompok eksperimen 6 peserta didik. Metode pengumpulan data yang digunakan dalam penelitian ini adalah skala empati yang disusun berdasarkan teori Eisenberg (2002) terdiri dari 22 item pertanyaan. Teknik analisis data untuk melihat peningkatan empati pada penelitian ini menggunakan uji Mann-Whitney dibantu program SPSS (Statistical Package for Social) versi 20.0 for windows.

\section{HASIL PEMBAHASAN}

Pada tanggal 11 januari 2019 penulis melakukan pretest dengan menggunakan skala empati di kelas VII B yang berjumlah 23 peserta didik. Berikut tabel hasil pretest: 
Tabel 1. Hasil Pretest

\begin{tabular}{|c|c|c|c|}
\hline Kategori & Interval & Frekuensi & $\begin{array}{c}\text { Persentase } \\
\text { (Dibulatkan) }\end{array}$ \\
\hline Tinggi & $66-68$ & 11 & $48 \%$ \\
\hline Sedang & $44-65$ & 6 & $26 \%$ \\
\hline Rendah & $22-43$ & 6 & $26 \%$ \\
\hline \multicolumn{2}{|c|}{ Jumlah } & 23 & $100 \%$ \\
\hline
\end{tabular}

Dari tabel 1 dapat diketahui terdapat 6 peserta didik mempunyai empati rendah, 6 peserta didik mempunyai empati sedang, 11 peserta didik mempunyai empati tinggi. Setelah itu peserta didik yang mempunyai kategori rendah dan sedang dibagi menjadi 2 kelompok yaitu kelompok eksperimen dan kelompok kontrol.

Tabel 2. Uji Mann-whitney Pretest Kelompok Eksperimen dan Kontrol

\begin{tabular}{|c|c|c|c|c|}
\hline \multicolumn{2}{|c}{ Hasil } & N & $\begin{array}{c}\text { Mean } \\
\text { Rank }\end{array}$ & \multicolumn{1}{c|}{$\begin{array}{c}\text { Sum of } \\
\text { Ranks }\end{array}$} \\
\hline Postest & $\begin{array}{c}\text { Kelompok } \\
\text { eksperimen }\end{array}$ & 6 & 9,00 & 54,00 \\
\cline { 2 - 5 } & $\begin{array}{c}\text { Kelompok } \\
\text { kontrol }\end{array}$ & 6 & 4,00 & 24,00 \\
\cline { 2 - 5 } & Total & 12 & & \\
\hline
\end{tabular}

Test Statistics $^{\mathrm{a}}$

\begin{tabular}{cc}
\hline & postes \\
\hline Mann-Whitney U & 3,000 \\
Wilcoxon W & 24,000 \\
Z & $-2,402$ \\
Asymp. Sig. (2-tailed) &, 016 \\
Exact Sig. [2*(1-tailed Sig.)] &, $015^{\mathrm{b}}$ \\
\hline
\end{tabular}

Berdasarkan hasil analisis Mann Whitney nampak bahwa skor Mann Whitney $U=$ 3,000, Nilai Z -2,403 dan nampak Asimp. Sig 2tailed $0,016<0,050$. Skor mean rank pada posttest kelompok kontrol 4,00. Kemudian skor mean rank pada posttest kelompok eksperimen adalah 9,00. Ada peningkatan skor mean rank kelompok eksperimen sebesar 5,00. Dalam penelitian ini, sikap empati tidak langsung tibatiba bisa muncul dan digunakan dalam kehidupan sehari-hari, tetapi melalui bermain peran dapat membantu peserta didikmengembangkan pola pikir yang fleksibel dan luas, mengasah kemampuan kognitif peserta didik khususnya pada nilai dan pemahaman empati secara lebih mendalam. Hasil penelitian ini sesuai dengan penelitian yang telah dilakukan oleh Yesi Marselina (2015), dengan judul "Layanan Bimbingan Kelompok Dengan Teknik Role Playing. Untuk Meningkatkan Empati Pada Siswa Kelas VII MTs Mathla'ul Anwar Bandar Lampung Tahun Ajaran 2017/2018" mengungkapkan bahwa empati peserta didik meningkat dilihat dari mean sebelum diberikan treatment 39 dan sesudah diberikan treatment 74 sehingga terjadi peningkatan 35 dengan demikian dapat dikatakan berhasil. Selain itu, penelitian yang dilakukan oleh Siti Hasinah dengan judul “ Penerapan Bimbingan Kelompok di Sekolah Untuk Meningkatkan Empati Siswa di MAN 3 Medan 2018” mencapai keberhasilan karena pada sebelum diberikan treatment 40 dan sesudah diberikan treatment 90 sehingga terjadi peningkatan 50 .

Empati sangatlah penting dalam menjalin hubungan dengan orang lain ataupun pergaulan, kemampuan ini bertujuan untuk memahami perasaan orang lain, menerima sudut pandang orang lain, menghargai perbedaan perasaan orang terhadap berbagai macam hal, menjadi pendengar dan penanya yang baik (Budiningsih 2004). Seseorang dikatakan mempunyai empati yang baik jika individu tersebut mempunyai motivasi menolong yang tinggi (Maxwell dalam Taufik, 2012).

Kesimpulan paling akhir dari penelitian ini yaitu, layanan BK dengan metode role play ini hanya sampai pada tahap membantu peserta didik membentuk nemahaman empati yang lebih mendalam, yang pada nantinya peserta didik sendiri yang akan mengeksplorasi dan mengembangkan dikehidupan sehari-hari. Dalam membentuk pemahaman empati secara mendalam para peserta didik dilatih untuk mengaplikasikan serta mencobakan melalui permainan peran (role play), guna role play dalam penelitian ini yaitu membentuk kebiasaan peserta didik 
melakukan sikap-sikap empati yang nantinya dapat berkembang dalam kehidupan seharihari.

\section{KESIMPULAN DAN SARAN}

Berdasarkan hasil pembahasan dalam bab IV, maka dapat diambil kesimpulan bahwa empati peserta didik SMP Stella Matutina Salatiga dapat meningkatkan secara signifikan pada kelompok eksperimen. Sebelum diberikan treatment mean pada kelompok eksperimen sebesar 6,33 dan mean pada kelompok kontrol 6,67. Setelah diberikan treatment terdapat peningkatan mean rank sebesar 5,00. Dari pre test 4.00 dan post test sebesar 9,00. Dengan koefisien Asymp.Sig (2-tailed) sebesar $0,016<0,050$ Peningkatan empati terjadi karena adanya treatmentberupa bimbingan kelompok yang dilakukan oleh kelompok eksperimen. Hal ini menunjukkan bahwa bimbingan kelompok dapat meningkatkan empati peserta didik SMP Stella Matutina Salatiga.

Berdasarkan hasil penelitian yang telah dilakukan maka, dapat dikemukakan beberapa saran bagi pihak yang terkait dalam penelitian ini yaitu:

\section{a. Guru Bimbingan dan Konseling di Sekolah}

Guru BK dapat memberikan layanan BK melalui metode bimbingan kelompokpada peserta didik yang mengalami masalah empati agar peserta didik semakin antusias dalam menerima layanan BK di sekolah.

\section{b. Bagi Subjek Penelitian}

Subjek penelitian khususnya kelas VII B SMP Stella Matutina Salatiga, diharapkan dapat lebih aktif mengikuti kegiatan layanan bimbingan kelompok, karena layanan ini sangat bermanfaat terutama untuk meningkatkan empati yang dimiliki peserta didik sehingga, nantinya peserta didik akan menjadi pribadi yang lebih baik dan berguna bagi masyarakat.

\section{c. Bagi Peneliti Selanjutnya}

Hasil penelitian ini menunjukkan bahwa ada peningkatan yang signifikan empati peserta didik SMP Stella Matutina
Salatiga setelah mengikuti layanan bimbingan kelompok. Peneliti selanjutnya dapat melaksanakan penelitian mengenai peningkatan empati melalui metode bimbingan kelompok.

\section{DAFTAR RUJUKAN}

Budiningsih, Asri. 2004. Belajar dan Pembelajaran. Yogyakarta: Rineka Cipta.

Dian Novianti Sitompul, 2015. Pengaruh Penerapan Layanan Bimbingan Kelompok Teknik Role-Playing Terhadap Perilaku Solidaritas Siswa Dalam Menolong Teman Di Sma Negeri 1 Rantau Utara T.A 2014/ 2015. Jurnal EduTech Vol .1 No 1 Maret 2015

Effendy, Meydian dan Endang Sri Indrawati, 2018. Hubungan Antara Empati Dengan Perilaku Agresif Pada Suporter Sepakbola Panser Biru Banyumanik Semarang. Jurnal Empati

Eisenberg, N.2002. Empathy and its Development. New York: Cambridge University Press.

Howe David. 2015. Empati Makna Dan Pentingnya. Penerbit Pustaka Pelajar Yogyakarta.

Istarani. 2011. 58 Pembelajaran Inovatif (Refrensi Guru dalam Menentukan Model Pembelajaran). Medan: Media Persada.

Marselina, Yesi. 2018, Layanan Bimbingan Kelompok Dengan Teknik Role Playing Untuk Meningkatkan Interaksi Sosial Pada Siswa Kelas Vii Mts Mathla’ul Anwar Bandar Lampung. Skripsi. Universitas Islam Negeri Raden Intan Lampung

Romlah, T. 2002. Teknik-Teknik Bimbingan dan Konseling Kelompok. Malang: Universitas Negeri Malang. vol.7, No. 3

Taufik. 2012. Empati Pendekatan Psikologi. Penerbit Raja Grafindo Persada Jakarta

Taufik, I. W. (2000). Hubungan Empati Dengan Intensi Prososial pada Peserta Didik-Siswi Muhammadiyah Mataram. Skripsi. Surakarta: Fakultas Psikologi. Universitas Muhammadyah Surakarta.

Tohirin. 2013 Bimbingan dan Konseling Di Sekolah Dan Madrasah (Berbasis Integrasi). Jakarta: PT. Grafindo Persada 
Hasinah, Siti. 2018. Penerapan Bimbingan

Kelompok di Sekolah Untuk

Meningkatkan Sikap Empati Siswa Di Man

3 Medan. Skripsi. Universitas Islam Negeri

Sumatera Utara 